\title{
Genesis of a KPC-producing Klebsiella pneumoniae after in vivo transfer from an imported Greek strain
}

F Barbier ${ }^{1,2,3}$, E Ruppé (etienne.ruppe@bch.aphp.fr) ${ }^{1,3}$, P Giakkoupi ${ }^{4}$, L Wildenberg' ${ }^{1}$, C Lucet ${ }^{5}$, A Vatopoulos ${ }^{4}$, M Wolff ${ }^{2}$, A Andremont ${ }^{1}$

1. Department of Bacteriology, EA3964 and National Reference Centre for Antimicrobial Resistances in Commensal Flora, BichatClaude Bernard Hospital (Assistance Publique-Hôpitaux de Paris) and Paris-7 University, Paris, France

2. Medical Intensive Care Unit, Bichat-Claude Bernard Hospital (Assistance Publique-Hôpitaux de Paris) and Paris-7 University, Paris, France

3. These authors contributed equally to this work

4. Department of Microbiology, National School of Public Health, Athens, Greece

5. Infection Control Unit, Bichat-Claude Bernard Hospital (Assistance Publique-Hôpitaux de Paris) and Paris-7 University, Paris, France

Citation style for this article:

Citation style for this article: Barbier F, Ruppé E, Giakkoupi P, Wildenberg L, Lucet JC, Vatopoulos A, Wolff M, Andremont A. Genesis of a KPC-producing Klebsiella pneumoniae after in vivo transfer from an imported Greek strain. Euro Surveill. 2010;15(1):pii=19457. Available online: http://www.eurosurveillance.org/

ViewArticle.aspx?Articleld=19457

We document here the in vivo transfer of bla ${ }_{\mathrm{KPC}-2}$ between intensive care unit-acquired and a commensal strain of Klebsiella pneumoniae in a French patient after his repatriation from Greece. This first report of in vivo transfer of a bla $a_{\mathrm{KPC}-2}$ between two $K$. pneumoniae strains raises further concerns about the spread of carbapenem resistance among Enterobacteriaceae.*

\section{Introduction}

Carbapenems are the cornerstone of therapy against multidrug-resistant (MDR) enterobacteria, notably those expressing extended-spectrum $\beta$-lactamases (ESBL). To date, enterobacterial strains producing Ambler class A Klebsiella pneumoniae carbapenemases (KPC) remain very scarce in western European countries and correspond almost exclusively to imported clones from endemic areas, namely, the United States, Israel and Greece [1]. The blaKPC genes are located in a set of plasmid-borne Tn4401-type transposons [2], with recent evidence of interspecies conjugative transfer [3,4]. Here, we provide the first evidence of in vivo transfer of bla $a_{\mathrm{KPC}-2}$ between two $K$. pneumoniae strains from a single patient, one imported from Greece and the other from the commensal flora, leading to the emergence of a new KPC-2producing strain in France.

\section{Case report and study}

A French man in his 7os who was travelling in Greece was admitted to the intensive care unit (ICU) of a hospital in Athens on 30 April 2009 (day o) for intestinal bleeding complicated by haemorrhagic shock and multiple organ failure. Several nosocomial infections occurred during his five-week long ICU stay in Athens, including a catheter-related bloodstream infection (BSI, day 25) due to a carbapenem-resistant $K$. pneumoniae strain that was also resistant to fluoroquinolones, co-trimoxazole, and aminoglycosides except gentamicin. This episode resolved after catheter removal and a one-week course of intravenous colistin. Subsequent clinical improvement allowed medical repatriation in France, and the patient was transferred to the ICU of a hospital in Paris (day 42). Intestinal carriage of MDR enterobacteria was routinely screened at admission by plating a rectal swab on ChromID ESBL medium (BioMérieux). One carbapenem-resistant $K$. pneumoniae strain (CHA-1) was isolated, and expressed the same co-resistances as the one involved in the BSI episode (Table). As the patient had never been hospitalised previously, we assume that he acquired the CHA-1 in the ICU in Athens.

The patient was discharged to a general medical ward on day 62. He did not receive carbapenems or other $\beta$-lactams after his transfer from Greece. On day 92, a second rectal swab was cultured on ChromID ESBL medium. Overnight growth yielded $K$. pneumoniae for which subsequent antibiotic susceptibility testing showed two distinct phenotypes. Subculturing recovered $\mathrm{CHA}-1$ and another $K$. pneumoniae strain designated as CHA-2 (Table). According to the latest breakpoints published by the European Committee on Antimicrobial Susceptibility Testing (EUCAST) [5], CHA-2 was resistant to ertapenem, intermediate susceptible to doripenem, and susceptible to imipenem and meropenem (Table).

Strains CHA-1 and CHA-2 were PCR-tested for all major $\beta$-lactamase-encoding genes, with subsequent sequencing of the PCR products. Both $\mathrm{CHA}-1$ and $\mathrm{CHA}-2$ carried bla ${ }_{\mathrm{KPC}-2}$ and bla ${ }_{\mathrm{TEM}-1}$. In addition, the Ambler class $\mathrm{B}$ carbapenemase-encoding gene bla $_{\mathrm{VIM}-1}$ was detected in strain CHA-1 (Table). 
We suspected that the strain CHA-2 had emerged by an in vivo co-transfer of $b l a_{\mathrm{KPC}-2} / b_{1} / a_{\mathrm{TEM}-1}$ from the ICUacquired strain $\mathrm{CHA}-1$ to a recipient wild-type commensal strain of $K$. pneumoniae. This hypothesis was supported by several facts: Firstly, conjugation assays in mixed broth cultures using the rifampicin-resistant Escherichia coli 53 strain as recipient and either CHA-1 or CHA-2 as donors resulted in $b l a_{\mathrm{KPC}-2 \mid}$ bla $a_{\mathrm{TEM}-1}$-positive $J 53$ transconjugants (conjugation frequency: $10^{-7}$ to $\left.10^{-8}\right)$, suggesting co-transfer of a plasmid carrying both genes. After extraction using the CompactPrep Plasmid Midi Kit (Qiagen), plasmids from both transconjugants yielded identical EcoRI-digestion patterns, arguing that CHA-1 and CHA-2 strains harboured the same bla $a_{\mathrm{KPC}-2} /$ bla $a_{\text {TEM-1 }}$-carrying plasmid. bla $a_{\mathrm{VIM}-1}$ could not be transferred from $\mathrm{CHA}-1$, as already experienced elsewhere [6]. Secondly, the swab from day 92 was re-plated on Drigalski agar. Twenty-five suspected K. pneumoniae were isolated, and those that did not grow on subcultures on ChromID ESBL medium were identified and tested for $\beta$-lactam susceptibility. Sixteen wildtype isolates of $K$. pneumoniae were thus collected and all yielded identical patterns in an enterobacterial repetitive intergenic consensus (ERIC)-PCR, suggesting that they were duplicates of a single wild-type $K$. pneumoniae strain, designated as BW1 (Table). Pulsed-field gel electrophoresis (PFGE) patterns of strains $\mathrm{CHA}-1, \mathrm{CHA}-2$ and $\mathrm{BW}_{1}$ were then compared to those of all KPC-2-producing pulsotypes of K. pneumoniae isolated to date in Greece (Figure).

The result indicated that (i) strain $\mathrm{CHA}-1$ belonged to a KPC-2/VIM-1-coproducing pulsotype that is currently spreading in Greek hospitals (pulsotype C) in parallel with the pulsotype $A$ that is the predominant KPC-2-producing pulsotype in Greece [6,7], (ii) CHA-2 did not match with any of the described Greek pulsotypes and (iii) KPC-2-producing strain CHA-2 and

TABLE

Antibiotic resistance phenotypes and acquired bla gene contents of enterobacterial strains described in this study

\begin{tabular}{|c|c|c|c|c|c|c|c|}
\hline & $\begin{array}{l}\text { K. pneumoniae } \\
\text { strain CHA-1 }\end{array}$ & $\begin{array}{l}\text { K. pneumoniae } \\
\text { strain CHA-2 }\end{array}$ & $\begin{array}{l}\text { K. pneumoniae } \\
\text { strain BW1 }\end{array}$ & $\begin{array}{l}\text { K. pneumoniae } \\
\text { strain TcBW1m }\end{array}$ & $\begin{array}{c}\text { E. coli } \\
\text { strain } 153\end{array}$ & $\begin{array}{c}\text { E. coli } \\
\text { strain TcJ53-1 }\end{array}$ & $\begin{array}{c}\text { E. coli } \\
\text { strain TcJ53-2 }\end{array}$ \\
\hline Origin & $\begin{array}{l}\text { Acquired } \\
\text { in Athens ICU }\end{array}$ & $\begin{array}{l}\text { Commensal } \\
\text { flora }\end{array}$ & $\begin{array}{c}\text { Commensal flora } \\
\text { (putative precur- } \\
\text { sor of strain } \\
\text { CHA-2) }\end{array}$ & $\begin{array}{l}\text { Conjugation } \\
\text { assay (donor: } \\
\text { CHA-1 / recipi- } \\
\text { ent: BW1m) }\end{array}$ & Collection & $\begin{array}{c}\text { Conjugation } \\
\text { assay (donor: } \\
\text { CHA-1 / recipi- } \\
\text { ent: J53) }\end{array}$ & $\begin{array}{l}\text { Conjugation } \\
\text { assay (donor: } \\
\text { CHA-2 / recipi- } \\
\text { ent: J53) }\end{array}$ \\
\hline $\begin{array}{l}\text { Date of isolation since } \\
\text { hospital admission }\end{array}$ & $\begin{array}{l}\text { Day } 42 \text { and } \\
\text { day } 92\end{array}$ & Day 92 & Day 92 & NA & NA & NA & NA \\
\hline Acquired bla genes & \begin{tabular}{|c|}
$b l a_{\mathrm{VIM}-1 \mathrm{~b}}$, \\
$\quad b l a_{\mathrm{TEM}-1}$ \\
\end{tabular} & $b l a_{\mathrm{KPC}-2}, b l a_{\mathrm{TEM}-1}$ & None & $b l a_{\mathrm{KPC}-2}, b l a_{\mathrm{TEM}-1}$ & None & $b l a_{\mathrm{KPC}-2}, b l a_{\mathrm{TEM}-1}$ & $b l a_{\mathrm{KPC}-2}, b l a_{\mathrm{TEM}-1}$ \\
\hline \multicolumn{8}{|c|}{ MIC values, $\mathrm{mg} / \mathrm{L}^{\mathrm{c}}$} \\
\hline Amoxicillin & $>256$ & $>256$ & 2256 & $>256$ & 2 & 2256 & $>256$ \\
\hline Amoxicillin + CLA & $>256$ & 32 & 1.5 & 32 & 2 & 24 & 24 \\
\hline Piperacillin & $>256$ & $>256$ & 6 & $>256$ & 0.75 & 256 & 256 \\
\hline Piperacillin + TZPe & $>256$ & 32 & 1 & 64 & 0.75 & 32 & 48 \\
\hline Cefotaxime & $>32$ & 2 & 0.047 & 2 & 0.023 & 4 & 4 \\
\hline Ceftazidime & $>256$ & 2 & 0.094 & 2 & 0.032 & 4 & 4 \\
\hline Aztreonam & 2256 & 8 & 0.032 & 6 & 0.016 & 4 & 4 \\
\hline Ertapenem & 132 & 2 & 0.006 & 2 & 0.006 & 0.75 & 0.75 \\
\hline Meropenem & 132 & 2 & 0.012 & 0.75 & 0.006 & 0.25 & 0.38 \\
\hline Doripenem & 232 & 1.5 & 0.016 & 0.75 & 0.006 & 0.25 & 0.25 \\
\hline Imipenem & 32 & 2 & 0.125 & 2 & 0.19 & 0.5 & 0.75 \\
\hline Tobramycin & 16 & 0.25 & 0.25 & 0.19 & 0.064 & 0.064 & 0.064 \\
\hline Amikacin & 16 & 1 & 1 & 1 & 0.38 & 0.25 & 0.25 \\
\hline Gentamicin & 1.5 & 0.5 & 0.5 & 0.5 & 0.094 & 0.094 & 0.094 \\
\hline Ciprofloxacin & $>32$ & 0.032 & 0.032 & 0.032 & 0.047 & 0.047 & 0.047 \\
\hline Cotrimoxazole & 132 & 0.064 & 0.064 & 0.064 & 0.004 & 0.004 & 0.004 \\
\hline Tigecycline & 0.5 & 1 & 1 & 1 & 0.5 & 0.5 & 0.5 \\
\hline Colistin & 0.125 & 0.125 & 0.125 & 0.125 & 0.19 & 0.125 & 0.19 \\
\hline
\end{tabular}

bla: beta lactamase; ICU: intensive care unit; NA: not applicable.

${ }^{a}$ Obtained by conjugation assays using a rifampin-resistant mutant of BW1 selected on Szybalski gradients (BW1m, MIC of rifampin > 250 $\mathrm{mg} / \mathrm{L}$ ) as recipient and CHA-1 as donor, and subsequent isolation on Drigaslki agar supplemented with cefotaxime (1mg/L) plus rifampin (250mg/L).

b The co-expression of VIM-1 and KPC-2 contributes to explain the higher MICs of $\beta$-lactams in strain CHA-1 when compared to the blaVIM-1egative/blaKPC-2-positive strain CHA-2;

' MIC: minimal inhibitory concentrations, as defined by E-test

${ }^{\mathrm{C}}$ CLA: clavulanic acid (2 $\left.\mathrm{mg} / \mathrm{L}\right)$

e TZP: tazobactam ( $4 \mathrm{mg} / \mathrm{L})$ 
wild-type strain BW1 displayed strictly identical Xbalfingerprints, except for one band of approximately 100 $\mathrm{kb}$ also observed in $\mathrm{CHA}-1$ that may correspond to the $b l a_{\mathrm{KPC}-2} / b l a_{\mathrm{TEM}-1}$-carrying plasmid. These data supported the role of $\mathrm{BW}_{1}$, the dominant wild-type $K$. pneumoniae strain within the digestive flora, as the $b_{1} a_{\mathrm{KPC} .2}$-negative precursor of CHA-2. Lastly, we confirmed that the bla $a_{\mathrm{KPC}-2} / b l a_{\text {TEM-1 }}$-carrying plasmid was transferable from CHA-1 to a rifampicin-resistant BW1 strain obtained on a Szybalski gradient (Table). Some limitations are yet to be considered since we cannot strictly exclude that CHA-2 could have been acquired in Greece and could have been missed in the swab taken on day 42 at admission in France. Likewise, we cannot exclude that acquisition of $\mathrm{CHA}-2$ could have occurred in France although reports on KPC-producing strains remain scarce to date.

This report raises further concerns about the diffusion of carbapenem resistance among enterobacteria.

\section{FIGURE}

XbaI-PFGE of $K$. pneumoniae strains CHA-1, CHA-2, BW1 and KPC-producing clones disseminated in Greek hospitals

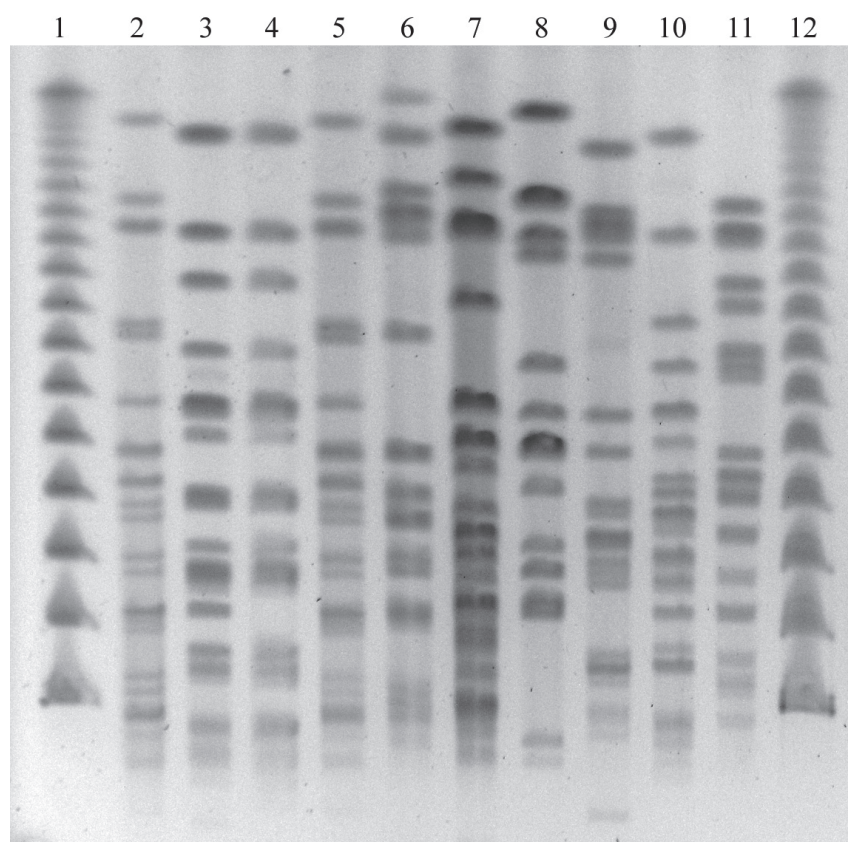

Lanes 1 \& 12: Lambda Ladder (New England Biolabs)

Lane 2: strain $\mathrm{CHA}-1 b l a_{\mathrm{VIM}-1}+b l a_{\mathrm{KPC}-2}$

Lane 3: strain CHA-2 bla ${ }_{\mathrm{KPC}-2}$

Lane 4: strain BW1wild type

Lane 5: strain $1780 b_{l} a_{\mathrm{VIM-1}}+$ bla $_{\mathrm{KPC}-2}$

Lane 6: strain $1797 b l a_{\mathrm{VIM}-1}+b l a_{\mathrm{KPC}-2}$

Lane 7: strain 1504 bla $_{\mathrm{KPC}-2}$

Lane 8: strain $1370 \mathrm{bla}_{\mathrm{KPC}-2}$

Lane 9: strain $1433 b_{\text {la }} a_{\mathrm{KPC}-2}$

Lane 10: strain 1516 bla $_{\mathrm{KPC}-2}$

Lane 11: strain 1643 bla $_{\mathrm{KPC}-2}$

Greek pulsotype $C$

Greek pulsotype $\mathrm{G}$

Greek pulsotype A

Greek pulsotype B

Greek pulsotype D

Greek pulsotype E

Greek pulsotype $F$
Indeed, that imported strains from endemic areas are able to spread blaKPC genes - even in the absence of $\beta$-lactam selective pressure, as in this patient - is worrisome, most notably for western European countries where the incidence of KPC-producing pathogens is still low.

\section{Acknowledgements}

This work was supported in part by the National Reference Centre for Antimicrobial Resistances in Commensal Flora.

*Erratum: This sentence was replaced on 14 January 2010

\section{References}

1. Nordmann P, Cuzon G, Naas T. The real threat of Klebsiella pneumoniae carbapenemase-producing bacteria. Lancet Infect Dis. 2009;9(4):228-36.

2. Naas T, Cuzon G, Villegas MV, Lartigue MF, Quinn JP, Nordmann $P$. Genetic structures at the origin of acquisition of the beta-lactamase blaKPC gene. Antimicrob Agents Chemother. 2008;52(4):1257-63.

3. Cai JC, Zhou HW, Zhang R, Chen GX. Emergence of Serratia marcescens, Klebsiella pneumoniae, and Escherichia coli isolates possessing the plasmid-mediated carbapenemhydrolyzing beta-lactamase KPC-2 in intensive care units of a Chinese hospital. Antimicrob Agents Chemother. 2008;52(6):2014-8

4. Rasheed JK, Biddle JW, Anderson KF, Washer L, Chenoweth C, Perrin J, et al. Detection of the Klebsiella pneumoniae carbapenemase type 2 Carbapenem-hydrolyzing enzyme in clinical isolates of Citrobacter freundii and K. oxytoca carrying a common plasmid. J Clin Microbiol. 2008;46(6):2066-9.

5. European Committee on Antimicrobial Susceptibility Testing. Breakpoint tables for interpretation of MICs and zone diameters. Version 1.0 December 2009. Available from: http:// www.eucast.org/fileadmin/src/media/PDFs/EUCAST_files/ Disk test documents/EUCAST breakpoints_v1.0 20091221. pdf

6. Giakkoupi P, Pappa O, Polemis M, Vatopoulos AC, Miriagou $\mathrm{V}$, Zioga A, et al. Emerging Klebsiella pneumoniae isolates coproducing KPC-2 and VIM-1 carbapenemases. Antimicrob Agents Chemother. 2009;53(9):4048-50.

7. Giakoupi P, Maltezou H, Polemis M, Pappa O, Saroglou $\mathrm{G}$, Vatopoulos A, et al. KPC-2-producing Klebsiella pneumoniae infections in Greek hospitals are mainly due to a hyperepidemic clone. Euro Surveill. 2009;14(21):pii=19218. Available from: http://www.eurosurveillance.org

* CHA-2 and BW1 pulsotypes only differ by a $\sim 100-k b$ band deemed to match the bla $a_{\mathrm{KPC}-2}$-carrying plasmid (also harboured by strains $\mathrm{CHA}^{\mathrm{KPC}-1}$ and 1780) [6].

PFGE: pulsed-field gel electrophoresis. 